\title{
ESTUDO DA FRAGILIZAÇÃO A QUENTE NOS AÇOS PRODUZIDOS PELA COMPANHIA SIDERÚRGICA NACIONAL*
}

Daniela Oliveira Mota Guimarães ${ }^{1}$ Carlaine Fonseca de Souza ${ }^{2}$

\section{Resumo}

As inclusões de sulfeto de ferro são indesejáveis no aço, pois são responsáveis por causar o fenômeno de fragilização a quente. A relação entre manganês e enxofre se torna de plena importância para o entendimento desse fenômeno. O presente trabalho teve como objetivo indicar a relação entre Manganês $(\mathrm{Mn})$ e Enxofre(S) mais adequada para a não ocorrência deste fenômeno, e explicar a influência dessa relação nas propriedades dos aços C-Mn. Estudou-se um aço C-Mn com a relação $\mathrm{Mn} / \mathrm{S} 50 \%$ menor do que a relação visada na Companhia Siderúrgica Nacional(CSN).

Palavras-chave: Manganês; Fragilização a quente; Ductilidade a quente.

\section{STUDY OF HOT SHORTNESS IN STEEL PRODUCED IN COMPANHIA SIDERÚRGICA NACIONAL}

\section{Abstract}

The iron sulfide inclusions in steel are undesirable because they are responsible for causing the hot shortness phenomenon. The ration between manganese and sulfur becomes full of importance for the understanding of this phenomenon. This study aimed to explore the ration between manganese $(\mathrm{Mn})$ and sulfur $(\mathrm{S})$ to the non-occurrence of this phenomenon along as the influence of this relationship on the properties of C-Mn steels. One steel was evaluated with respect to Mn/S 50\% lower than the target relation in the Companhia Siderurgica Nacional.

Keywords: Manganese; Hot shortness; Hot ductility.

1 Engenharia Metalúrgica, Engenheira Metalurgista, Engenheira de Produtos de Laminação a frio e galvanizados, Gerência de Processos da Laminação, Companhia Siderúrgica Nacional - CSN, Volta Redonda, Rio de Janeiro, Brasil.

2 Engenharia Metalúrgica, Engenheiro Metalurgista, Gerente de Processos de Laminação da Companhia Siderúrgica Nacional, Gerência de Processos da Laminação, Companhia Siderúrgica Nacional - CSN, Volta Redonda, Rio de Janeiro, Brasil. 


\section{INTRODUÇÃO}

A razão entre o manganês e enxofre para a não fragilização a quente dos aços é muito discutida entre diversos pesquisadores, e opiniões distintas são formadas.

As inclusões de sulfetos de ferro são indesejadas nos aços por que contribuem para o fenômeno de fragilização a quente.

A motivação desse trabalho foi de buscar a minimização do consumo de um recurso natural não renovável, iniciativa que está alinhada com a redução de custo e o aumento de competitividade da empresa. Para isto, foi necessário determinar a mínima relação $\mathrm{Mn} / \mathrm{S}$ para evitar a fragilização a quente considerando também as propriedades dos aços C-Mn de qualidade comercial.

\subsection{Fragilização a Quente}

De uma forma geral sabe-se que sulfeto de ferro possui um ponto de fusão muito baixo, em relação ao aço, de modo que sua presença nos processos de conformação mecânica a quente, realizados normalmente a $1100^{\circ} \mathrm{C}$ (laminação a quente) confere ao aço a chamada "fragilidade a quente", defeito que deve ser evitado pra permitir uma conformação mecânica adequada [1]. Na ausência de manganês, o enxofre prontamente combina-se com ferro para formar sulfeto de ferro. Nestas condições, faz-se necessário a adição de manganês, pois o enxofre tem maior afinidade eletrônica com esse elemento do que pelo ferro, e o sulfeto de manganês formado possui ponto de fusão de aproximadamente $1600^{\circ} \mathrm{C}$, eliminando a fragilidade a quente. Além disso, o MnS formase em partículas diminutas, relativamente plásticas deformando-se no sentido de laminação.

O sulfeto de ferro puro, uma fase que nucleia nos limites de grão, é formado no final da solidificação do aço e possuí forma de redes. A formação deste sulfeto sempre será prejudicial ao aço, levando ao sucateamento de todo o material. Já o sulfeto de manganês pode ser prejudicial às propriedades mecânicas do material ou não, dependendo do seu formato, e tamanho. Para a usinagem é desejável que se tenha grandes inclusões de MnS para que não tenha a quebra de cavaco, entretanto para aços que exija um mínimo de ductilidade, essas inclusões são indesejáveis. As inclusões de sulfetos de manganês podem afetar drasticamente a ductilidade do material.

O manganês aumenta o campo austenitico, e possui um efeito endurecedor por solução solida na ferrita. Este também diminui a temperatura de transformação da austenita, causando assim um leve refinamento dos grãos ferríticos aumentando a resistência mecânica e ductilidade a quente do material [2].

A formação de sulfeto de ferro ou sulfeto de manganês e as características que estes sulfetos dão ao material vão depender da relação de $\mathrm{Mn} / \mathrm{S}$. Não existe uma homogeneidade descrita pelos autores deste tema de relação exata de $\mathrm{Mn} / \mathrm{S}$, ou uma relação fixa. Nota-se que existe uma diferença entre a relação $\mathrm{Mn} / \mathrm{S}$ para a não fragilização a quente, e a relação $\mathrm{Mn} / \mathrm{S}$ que refletem nas propriedades mecânicas do aço. Nos próximos parágrafos serão mostradas diferentes relações de Mn/S sugeridas por diversos autores.

Sugere-se que a relação de Mn/S seja superior a 4 para garantir a formação de MnS[1]. Assim como descrito do ASM Metals Handbook, a relação Mn / S adequada pode ser calculado com a Equação $\mathrm{Mn}=1,7 \times$ \% $+0,15$ [3]. Para relações de $\mathrm{Mn} / \mathrm{S}$ menores do que 1 , o FeS puro é também formado [4].

Assim como escrito em Ferroalloys \& Alloying Additives Online Handbook, aços com uma razão $\mathrm{Mn} / \mathrm{S}$ de, pelo menos, 8/1não irá apresentar fragilização a quente[2]. 
De acordo com o artigo, "FeS- MnS in Relationship in the Presence of Excess Iron" a composição química dos MnS e FeS são complexas [5]. Por isso não podemos considerar uma análise simplificada, considerando pesos atômicos de $\mathrm{Fe}, \mathrm{S}$ e $\mathrm{Mn}$, o que nos daria uma relação em peso de 2/1 para a não formação de FeS. Na formação destes sulfetos ocorre a formação de ternários Fe-Mn-S, como mostra a figura 1.

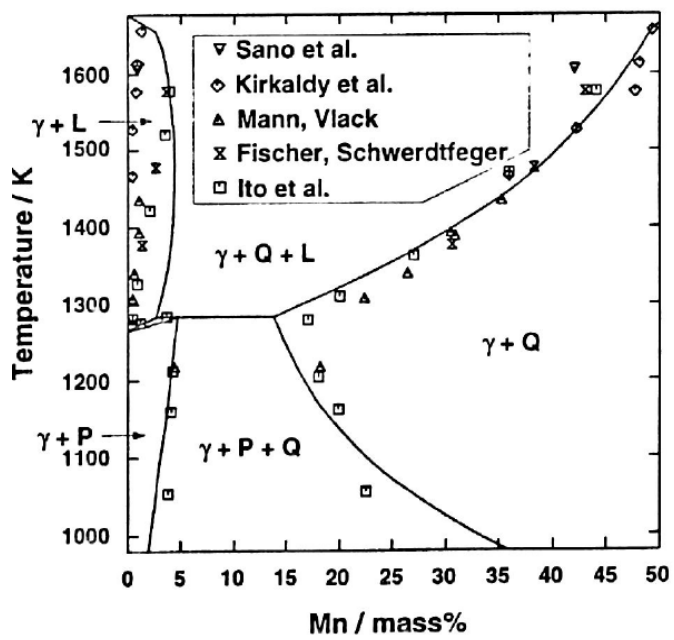

Figura 1 - Diagrama MnS-FeS com a presença de ferro livre (atividade do ferrro=1) calculado por Ohtani e colaboradores superposto a dados experimentais e diagrama compilado por Van. [5]

\subsection{Influência do Manganês na Ductilidade a Quente do Material}

A relação Mn/S vai muito além da fragilização a quente, mas ela interfere drasticamente na propriedade mecânica do material. Segundo o artigo de Wilber e colaboradores, a ductilidade é sensivelmente afetada pela a variação de composição química [6].

Um parâmetro muito importante que influencia a ductilidade a quente do material é o ciclo térmico que é submetido o aço. Quando o material sofre um ciclo de reaquecimento a sua ductilidade aumenta significantemente, e isso ocorre no processo de laminação comum. Quando as placas saem do lingotamento continuo são resfriadas ao ar livre para depois serem laminadas, onde primeiramente são reaquecidas entre as temperaturas de $1100^{\circ} \mathrm{C}$ a $1200^{\circ} \mathrm{C}$. Logo a ductilidade no processo de laminação é favorecida, diferentemente de quando se tem um lingotamento acoplado a laminação a quente (CSP). A figura 2 mostra a influência de diferentes ciclos térmicos na ductilidade a quente do material. 


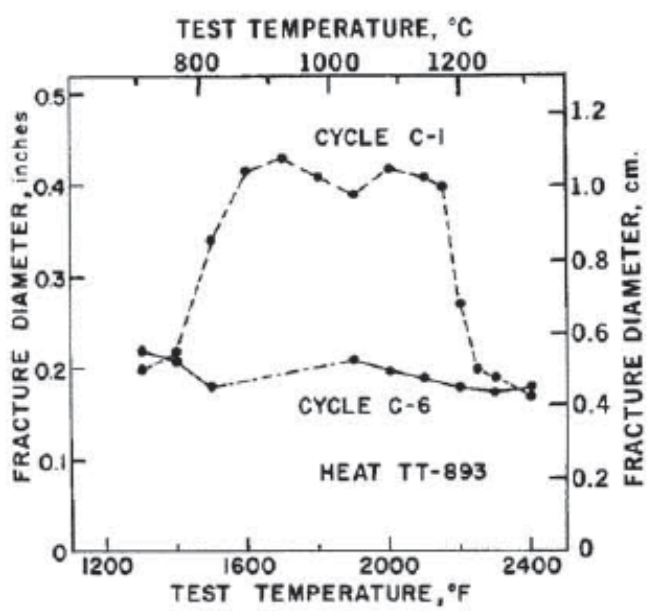

Figura 2 - Comparação do tamanho do diâmentro da fratura entre os ciclos C1 e C6 no material Heat TT883. [6]

\section{MATERIAIS E MÉTODOS}

\subsection{Materiais}

Foram testadas 3 placas com a relação $\mathrm{Mn} / \mathrm{S}$ reduzida $50 \%$ da faixa média visada pela CSN.

Inicialmente foi feita uma análise de baumann nas 3 placas, para verificar a sanidade interna do material e verificar quais os pontos mais críticos para utiliza-los nas análises. A dimensão da amostra de baumman é conforme o esquema a seguir:

\section{Dimensões $(\mathrm{mm})$}

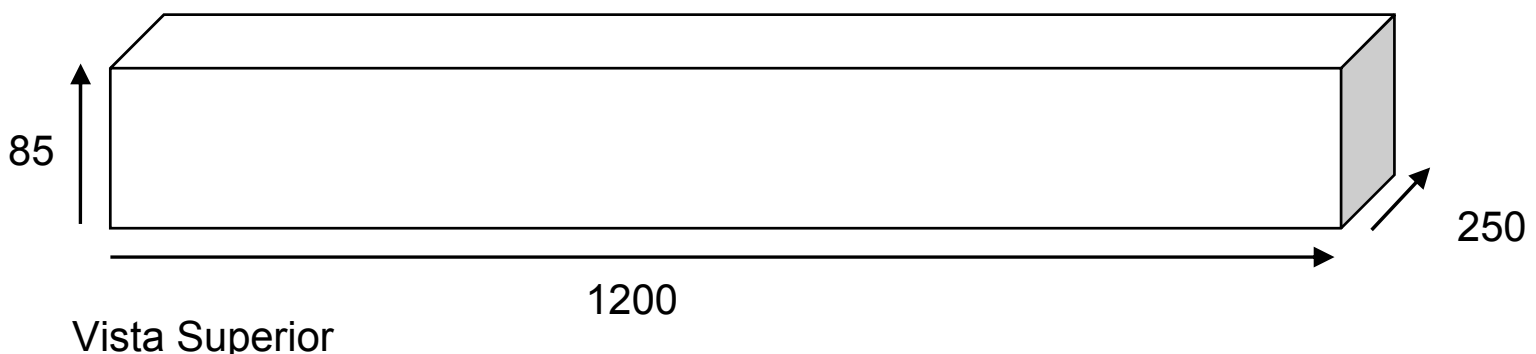

Vista Superior

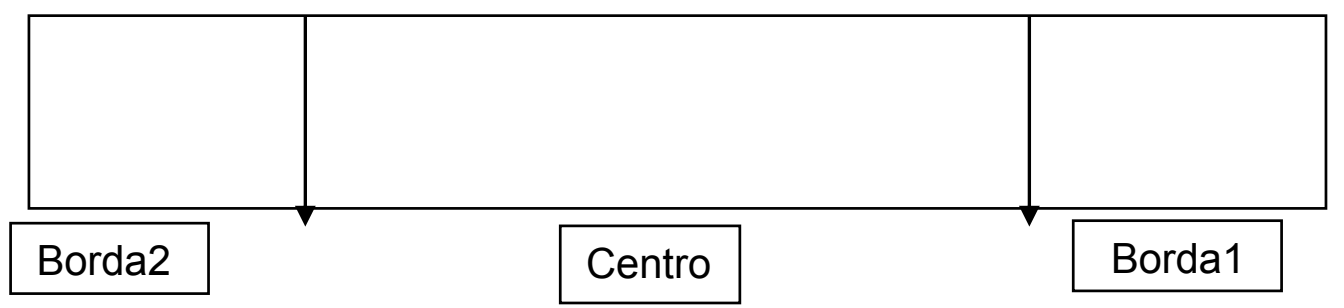

Para a análise em escala piloto, a partir da placa foram feitos lingotes e corpos de prova de formato cilíndrico para a análise de ductilidade a quente do material. 


\subsection{Métodos}

\subsubsection{Tratamento Térmico}

Nos lingotes foram realizados os tratamentos térmicos em temperaturas de $1100^{\circ} \mathrm{C} \mathrm{e}$ $1250^{\circ} \mathrm{C}$, utilizando um período de encharque de $2 \mathrm{horas}$, em seguida foram resfriadas em salmoura para congelamento da microestrutura. Esse procedimento deve-se ao fato de que se houver a formação de sulfetos de ferro nessas elevadas temperaturas com 0 congelamento das microestruturas eles ficaram retidos. Este procedimento foi realizado no forno BRASMET da Companhia Siderúrgica Nacional.

Após o tratamento térmico foram feitas análises metalograficas a fim de ver as morfologias dos sulfetos formados. A análise de EDS (espectrômetro de energia dispersiva) também foi feita para ver a composição química dos precipitados presentes.

\subsubsection{Laminação Piloto}

Alguns lingotes foram aquecidos em diferentes temperaturas, $1150^{\circ} \mathrm{C}$ e $1250^{\circ} \mathrm{C}$ no forno BRASIMET. O período de encharque foi de aproximadamente 2,5 horas. As temperaturas de reaquecimento foram escolhidas de acordo com as situações normais e críticas que ocorrem dentro da Companhia Siderúrgica Nacional.

Após o reaquecimento das amostras, a laminação a quente foi realizada, no laminador piloto da Oficina Mecânica do Centro de Pesquisas na Companhia Siderúrgica Nacional, simulando a laminação a quente da usina. Foram dados 7 passes de laminação com as reduções proporcionais a que ocorre no laminador de tiras á quente da CSN.

Após a laminação piloto foi feita também a analise metalografica no MEV (microscópio eletrônico de varredura) e analise de EDS nos precipitados presentes.

\subsubsection{Análise de Ductilidade a Quente}

Com os corpos de provas cilíndricos foram feitos ensaio de ductilidade a quente na Maquina GLEEBLO 360, no Laboratório Nacional de Nanotecnologia. Foi testado a ductilidade em 4 diferentes temperaturas e quatros tipos de relações Mn/S.

Foi realizada a análise da fratura em todos os corpos de provas.

\subsubsection{Laminação em Escala Industrial}

Após as analises em escala piloto, foram laminadas 3 placas com a relação manganês enxofre reduzida.

Essas placas seguiram os fluxos:

Laminador de tiras a quente\#2 - Laminador de tiras a frio\#3 - Linha de zincagem\#3.

Laminador de tiras a quente\#2 - Laminador de tiras a frio\#1 - Linha de recozimento contínuo\#1 - Laminador de encruamento\#4 - Linha de estanhamento eletrolítico.

\section{RESULTADOS E DISCUSSÃO}

\subsection{Resultados em Escala Piloto}

\subsubsection{Reaquecimento de Lingotes}

Os lingotes sofreram tratamentos térmicos a $1100^{\circ} \mathrm{C}$ e $1250^{\circ} \mathrm{C}$, e resfriadas em salmoura para congelamento da microestrutura. As amostras foram levadas para analises de EDS, com o intuito de identificar os elementos químicos presentes nos precipitados, e verificar se houve a ocorrência de sulfeto de ferro.

Avaliando a morfologia dos precipitados, concluímos que não houve a formação do sulfeto de ferro, pois os precipitados se encontram com a morfologia globalizadas, conforme mostra a figura 3. 


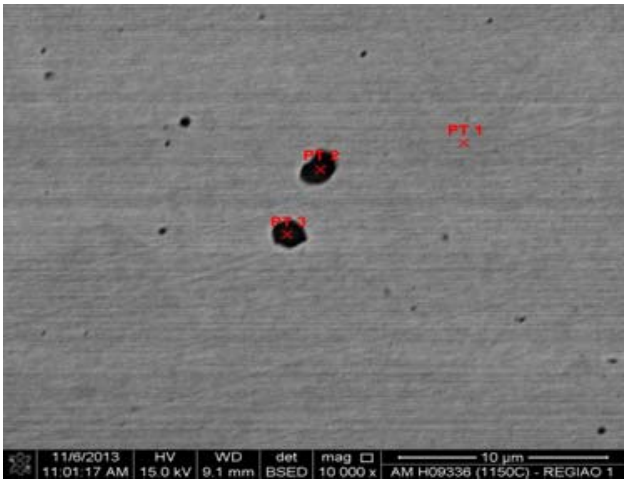

Figura 3 - Precipitados Globalizados nos lingotes tratados termicamente

Em todos os lingotes independentes da temperatura de encharque a morfologia globalizada foi encontrada.

Para a identificação da composição química dos precipitados formados foi feita a análise de EDS, em nenhum momento se viu a presença de sulfeto de ferro puro no material, e sim a presença de um sulfeto rico em manganês, como mostra a figura 4.

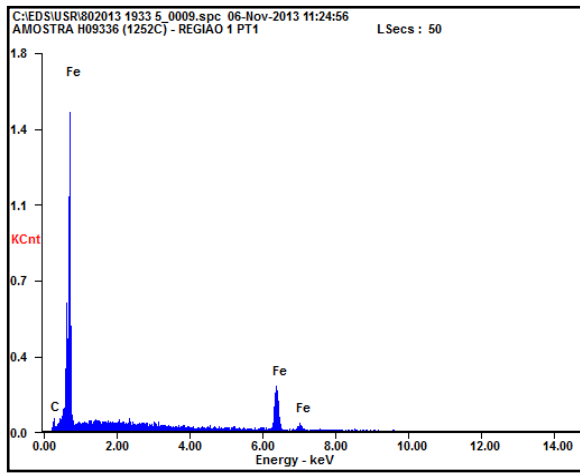

a)Analise de EDS no ponto 1

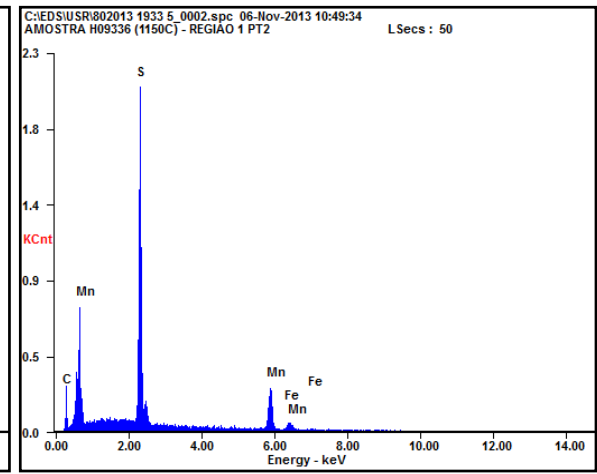

b)Análise de EDS no ponto 2

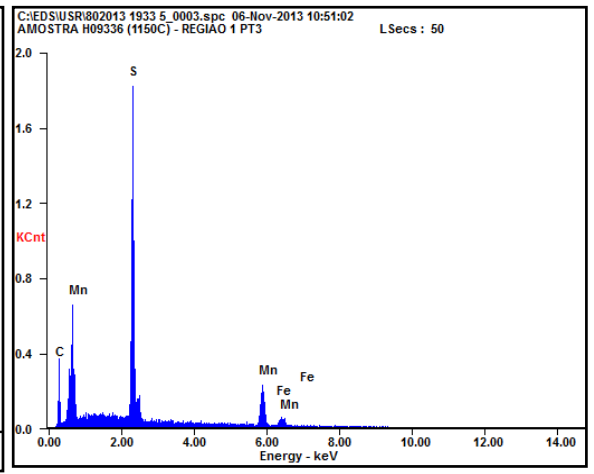

c) Analise de EDS no ponto 3

Figura 4 - Analise de EDS nos precipitados dos lingotes.

\subsubsection{Laminação Piloto}

A primeira análise na laminação a quente foi visual, onde se verificou que não houve a ocorrência de fragilização a quente nas seis amostras laminadas. Como mostra a figura 5.

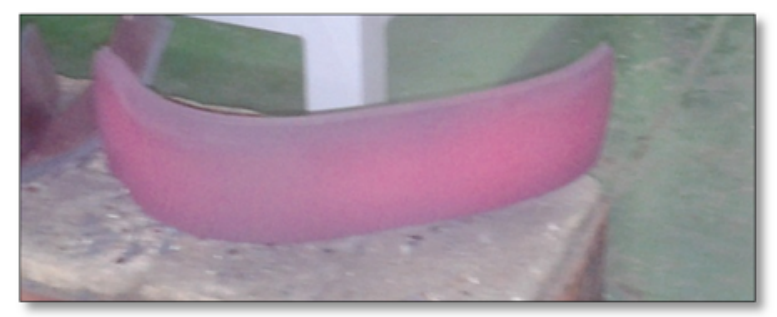

Figura 5 - Lingote após laminação.

Após a laminação piloto, a superfície da tira foi analisada, e foram escolhidas regiões para metalografia realizadas no microscópio óptico.

A primeira análise realizada foi a análise de inclusões, como mostra a figura 6 

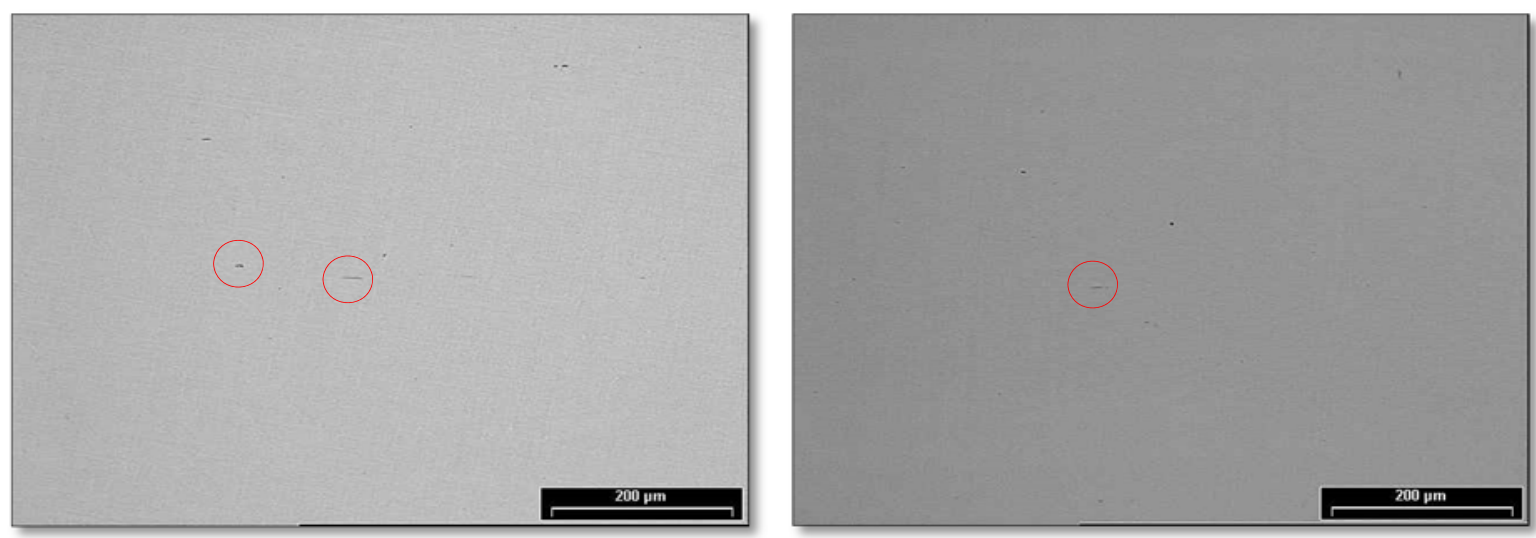

Figura 6 - Inclusões de Sulfetos

A classificação dos sulfetos encontrados foi de $1 / 2$ Fino, segunda a tabela de classificação de inclusão do Copaert.

De uma maneira geral, o material estava "limpo", ou seja, havia uma quantidade insignificante de inclusões para um aço C-Mn.

A análise metalografica também foi feita nas amostras laminadas a quente. Não foi encontrada nenhuma anormalidade nas microestruturas analisadas. A imagem metalográfica é mostrada na figura 7a. Foi medido o tamanho dos precipitados, imagem $7 \mathrm{~b}$, todos os precipitados medidos não passaram da ordem de nanômetro, se tratando assim de precipitados finos, favorecendo a propriedade mecânica do material.

Foi realizada a analise de EDS para determinar a composição química dos precipitados, mostrada na imagem 8.

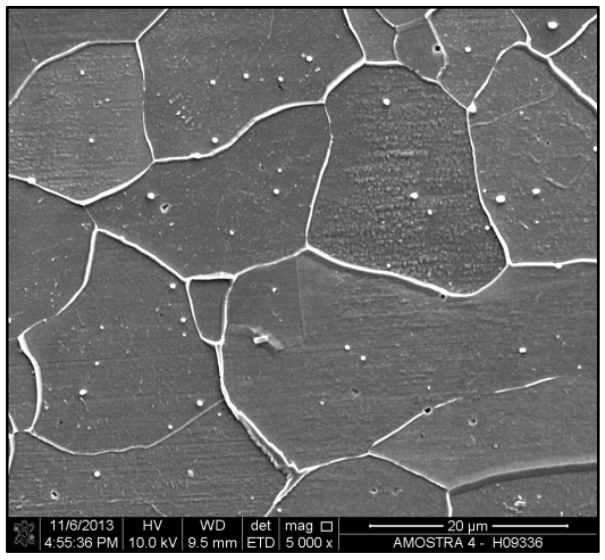

a) Microestrutura da matriz ferritica com precipitados

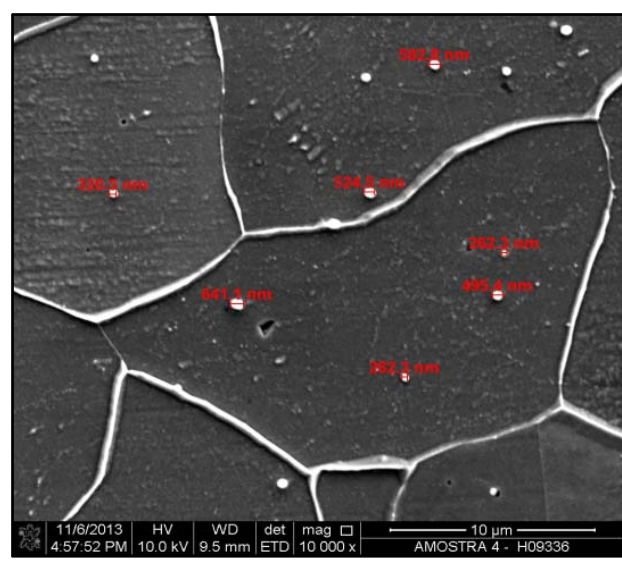

b) Medida dos precipitados dentro da matriz ferrítica

Figura 7 - Microestrutrura das amostras laminadas em escala piloto 


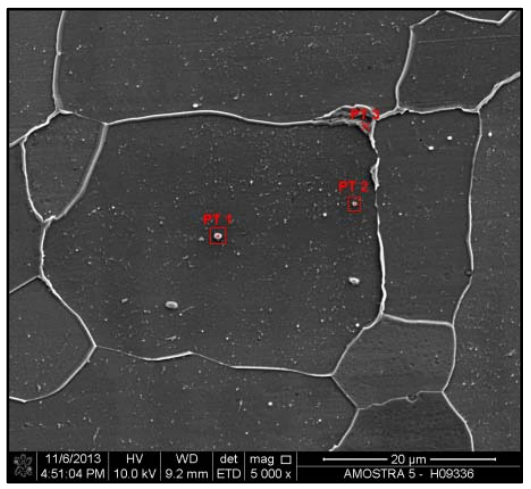

a)Precipitados de sulfetos na matriz ferritica.

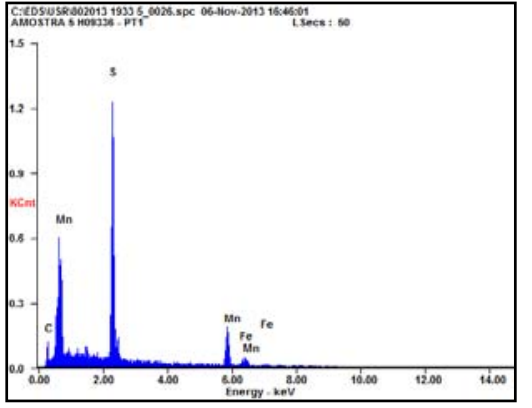

b) EDS no ponto 1

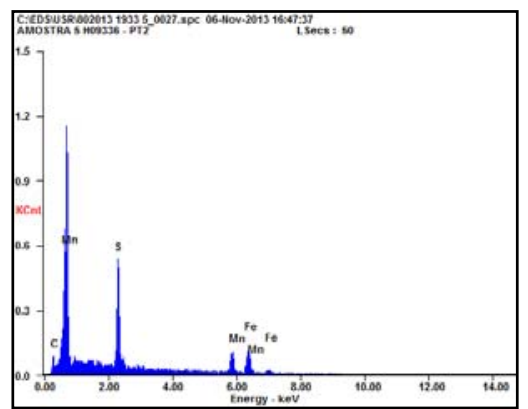

c)EDS no ponto 2

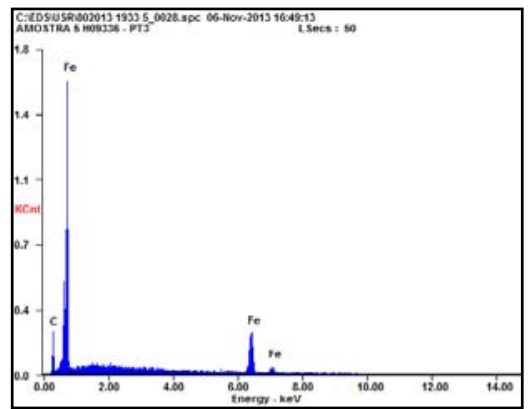

d) EDS no ponto 3 (matriz)

Figura 8 - Análise de EDS nos precipitados

Os precipitados encontrados tratavam-se de sulfeto de manganês.

\subsubsection{Ensaio de Ductilidade a quente}

Foram analisados CP's com diferentes relações Mn/S.

Todos os CP's tiveram uma fratura dúctil, figura 9a, com a presença de "dimples", na qual originam-se quando ocorre uma fratura intragranular, mostrado na figura $9 \mathrm{~b}$.

Não havendo diferença significativa de ductilidade a quente para as composições testadas.
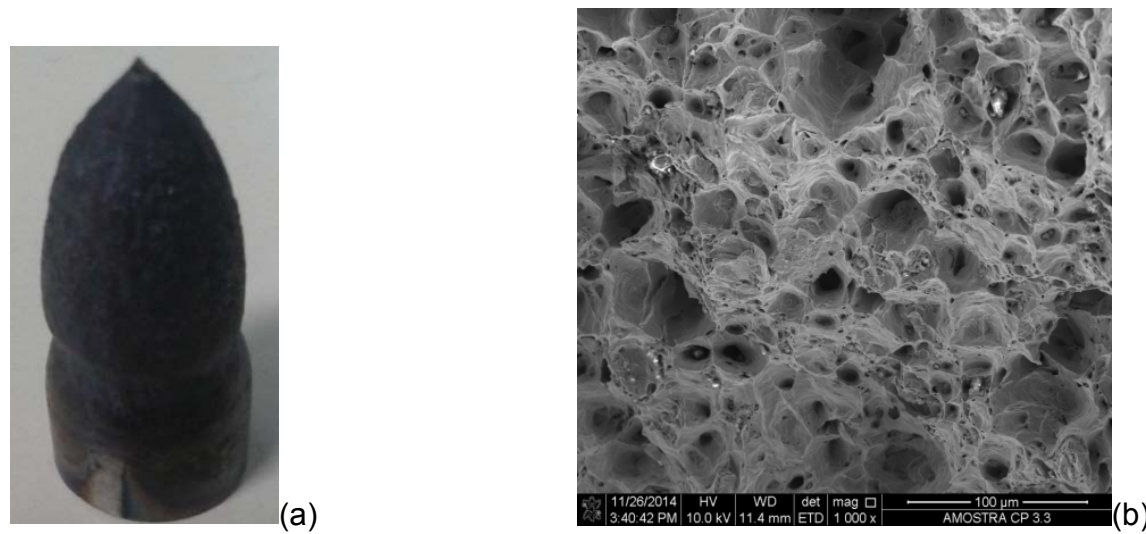

Figura 9 - (a) Imagem do CP com relação Mn/S 50\% relação menor que a usual na CSN, após ensaio de ductilidade a quente na gleeblo; (b) metalografia após a fratura do CP com $50 \%$ menor que praticado na CSN.

\section{2 - Laminação em Escala Industrial}

Ao total, 3 placas foram laminadas com a relação $\mathrm{Mn} / \mathrm{S}$ reduzida. O material foi testado a espessuras finais a frio de $1,50 \mathrm{~mm}$ e $0,18 \mathrm{~mm}$.

O acompanhamento da tira foi feito em todos os equipamentos, algumas imagens são mostradas na figura10. 


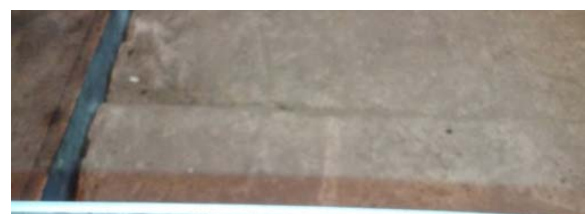

a)Inspeção da tira após o laminador de tiras a quente

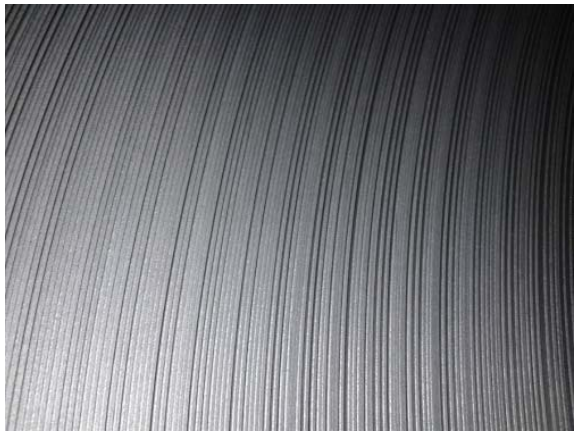

b) Inpeção da borda da tira após da linha de decapagem

Figura 10 - Imagens da tira com a relação $\mathrm{Mn} / \mathrm{S}$ reduzida

A metalografia do material laminado a quente foi realizada, e nenhuma anormalidade foi encontrada, figura 11.

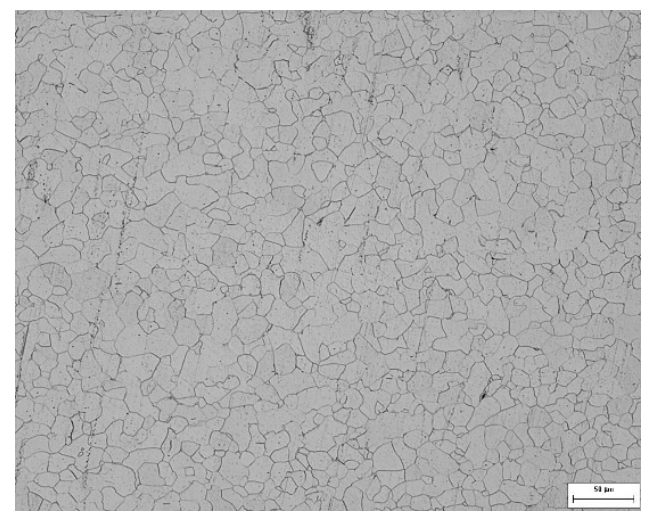

Figura 11- Matriz ferritica do aço com relação $\mathrm{Mn} / \mathrm{S}$ reduzida

\section{CONCLUSÃO}

Existe um grande paradoxo no qual a relação entre manganês e enxofre adequada para a não ocorrência de fragilização a quente. Há controvérsias nas interpretações de muitos autores na relação $\mathrm{Mn} / \mathrm{S}$ adequada para a não ocorrência da fragilização a quente com a perda de ductilidade que ocorre no material quando essa relação diminui.

$\mathrm{Na}$ laminação piloto verificou-se que a fragilização a quente não ocorreu, e em seguida este efeito confirmou-se quando as placas com relação $\mathrm{Mn} / \mathrm{S}$ reduzida foram laminadas em escala industrial.

Os resultados das análises realizadas nas placas, produzida na companhia siderúrgica nacional, com a relação manganês enxofre reduzida, confirmam a não formação do sulfeto de ferro.

Todo o sulfeto analisado tratou-se de sulfeto de manganês, a maioria deles eram precipitados finos e dispersos na matriz da ordem de nanômetros.

Em relação às inclusões, o material estava completamente limpo contendo poucos sulfetos, aluminatos e óxidos em uma forma geral.

A ductilidade a quente do material não foi afetada quando comparado com as relações entre manganês enxofre já utilizados na CSN para materiais C-Mn utilizado para fins comerciais.

$\mathrm{Na}$ microestrutura não foi evidenciado qualquer fator que sugerisse indícios de fragilização a quente ou perda de ductilidade a quente. 


\section{Agradecimentos}

Agradecemos ao Centro Nacional de Pesquisas em Engenharia de Materiais (CNPEM Campinas - SP), de uma maneira especial ao Laboratório Nacional de Nanotecnologia (LNNano) por toda a assistência fornecida nos ensaios de ductilidade a quente realizados na máquina Gleeble 360.

\section{REFERÊNCIAS}

1 Chiaverino V. Aços E Ferros Fundidos, $7^{a}$ Edição, Abm - Assoc. Bras. De Matalurgia, 2012

2 Metals Handbook, vol.14, Forming and Forging, 9a. ed., ASM Int., 1.988.

3 Ferroalloys \& Alloying Additives Online Handbook - AMG Vanadium, www.metallurgvanadium.com/manganesepage.html, (acessado em 10 de maio de 2011)

4 Roesch K. Stahl Eisen, No. 24, 1957, p 1747

5 Mann GS, Van Vlack LH. FeS-MnS Phase Relationships in the Presence of Excess Iron. Metallurgical Transactions B. 1976;7B:469-75.

6 Wilber GA, R. Batra W. F. Savage WJ. Childs. The effects of thermal history and composition on the hot ductility of low carbon steels. Metallurgical Transactions $A$ September 1975, Volume 6, Issue 9, pp 1727-1735. 